\title{
Why IT Doesn't Appeal To Young Women
}

\author{
JUDITH SYMONDS \\ The Open Polytechnic of New Zealand, symjud@topnz.ac.
}

\begin{abstract}
Much is written about the glass ceiling encountered by female IT professionals and associated strategies to remove such barriers. But what is the worth of such efforts when many women don't find IT appealing? This study uses an exploratory research design to discover why young women don't choose careers in IT. The young women in this study were aware of the benefits of a career in IT. However, the perception that a career in IT involves little communication and social skill steers young women away from a professional IT career.
\end{abstract}

\section{CAREERS IN IT}

Career prospects in IT are promising. An estimated 30,000 IT jobs sit vacant in Australia alone [5]. IT professionals are blessed with great jobs, great salaries and the opportunity to travel the globe. Despite the vast opportunities and favourable conditions, IT careers still appear to lack appeal for many.

Women, in particular are said to be suited to a career in IT. The essential qualities of a good IT professional are relationship management and communication skills [5]. Many more women than men are regarded as being good listeners, good communicators and interested in relationships [16]. Yet there are many less women than men employed as IT professionals. In Australia it is estimated that the female to male ratio in IT careers is $1: 9$.

It appears that there are many opportunities in IT for women. The aim of this research was to investigate the reasons why women didn't undertake a 
career in IT and make some recommendations for making IT careers more appealing to women.

Before providing details of the research method undertaken, it is necessary to present some of the literature in this area and the previous studies undertaken on this topic. After the data collection procedure has been outlined, the results of the study are presented along with conclusions from the study and some recommendations for promoting a career in IT to young women.

\section{PREVIOUS LITERATURE}

This section firstly investigates the perceptions about IT professionals of both the society at large and in particular those of young women. Justification is then provided for why most perceptions are formed and career decisions made during junior high school. Issues that concern female IT professionals are also explored. Finally, the findings of studies investigating career choice in young women are presented with a particular view to identifying the issues suggested by these studies as useful areas for further study.

IT professionals are perceived as proud, arrogant, secretive and unable to speak in everyday English [11]. Young women pick up on this and studies show that women feel IT is 'nerdy' [12]. Yet, still other studies show that female entrepreneurs are strong users of IT in their business [1]. Perhaps the most influential factor in this equation is very simply, the perceptions of society. These perceptions are widely spread throughout society, being evident in tertiary and secondary education.

Many IT careers follow on from university education. The disappointing male to female ratio in industry is reflected in undergraduate enrolments in Computer Science courses in South Africa [18], the United States [6] and Britain [2]. Even in business computing courses at the University of Southern Queensland, men outnumber women 4:6.

In most cases, students make choices about their careers before they enter into tertiary education institutions. It is suggested that most career choices stem from behaviour in middle school where children are at the ages of 11 through 14. During middle school, peer pressure tends to direct girls away from computers and computing is much more alluring for young men than for young women [6]. Prerequisite requirements of tertiary institutions, the influences of peer pressure and the pressures of society suggest it is important to address career perceptions at a secondary school level.

There are several issues related to computing careers that may influence women not to choose a career in computing. Men are often passionate about 
computers, however women use computers as tools for solving problems [6] which may also lead to a lack of experience in computer use [9]. A lack of experience is hard to overcome due to the culture of the elite computer user, which threatens to alienate new recruits to the discipline [14]. Women IT professionals must also overcome issues of physical safety, low self-esteem or confidence, lack of role models, cases of gender discrimination, perceived preference for male IT professionals and difficulties in balancing career and family responsibilities $[7,8,14,17]$.

There have been two recent studies of the career perceptions of secondary schoolgirls. A study of secondary school girls in Norway explored the process the girls undertook when choosing subjects for specialisation [15]. A similar Australian study conducted by Ryan [17], concluded that students, even before they attended, were generally well informed in the area of communication, opportunities for creativity, and the ability of women to program as well as men. However, the students were generally unsure if IT professionals worked alone and whether they mostly wrote programs.

The measures of awareness undertaken thus far indicate that the Australian students have access to at least some of the information necessary to make an informed career choice. However, as suggested by Ryan [17], further research needs to be undertaken to determine which of these aspects are appealing.

\section{METHOD}

The purpose of this study was to further explore the perceptions of female secondary students about computers and a career in computing. This section outlines the research method employed and the data collection procedures used to justify their appropriateness for this study.

The complex and exploratory nature of this research problem led to the choice of a qualitative research method. Data collection was undertaken during the annual Girls in Maths and Science Summer School at the University of Southern Queensland where the girls participated in a wide range of activities related to maths and science [4]. The study provides useful data about the perceptions of the participants of the school, which could be used to enhance activities and refine the focus of the school.

In this study, focus groups were conducted with four groups of eight participants from a range of backgrounds, as suggested by Morgan [13] and repeated when the students had undertaken activities as suggested by Krueger [10]. The participants of the school are chosen from approximately 350 applications from both state and private schools across Queensland [3]. 
The questions in the focus group followed the accepted path of opening questions, introductory questions, transition questions, key questions and ending questions as suggested by Krueger [10]. A short ice-breaking question was used after the initial introduction of the focus group to encourage the group to interact. Then participants discussed what they like and do not like about computers. The next set of questions asked them about their perceptions of a job in computing, their intentions in following a career in computing and to form a list of five positive and five negative things about a job in computing. During the post interview, participants discussed issues involving a career in computing after having participated in the activities.

\section{FINDINGS}

This section reports what the participants found appealing about computers, what frustrated them about computers, possible careers in IT, appealing aspects of IT careers and the disadvantages of working with computers. Finally, some social issues associated with working with computers were explored.

Initially, it was helpful to establish the perception of computers amongst the participants. This information is presented in Table 1. Generally, the participants found the computer to be a very productive tool for schoolwork and they used the Internet to obtain information and to chat and E-mail friends. The participants mentioned that they liked to play games but the only specific game that was ever mentioned was a windows card game.

Table 1 Perception of Computers

\begin{tabular}{|l|l|}
\hline Positive Issues & Negative Issues \\
\hline Productive tool & Slow processing time \\
Information on the & Hardware and system \\
Internet & Failure \\
Social chat with friends & Difficult to use \\
Play games & New programs to learn \\
& Health concerns \\
\hline
\end{tabular}

The participants were quick to identify what they didn't like about computers. Mostly they didn't like system or hardware problems or slow response times. Some were genuinely concerned about health issues including sore eyes and headaches and the effort to continually update their skills. After establishing the participants' perceptions of computing, these issues were expanded into their perceptions regarding a career in IT. The participants' perceptions regarding a career in IT are summarised in Table 2. When asked about what jobs they thought were available in computing, all 
the groups responded with secretarial jobs. Some mentioned small business and various jobs in training and education. Few groups responded with technical jobs such as designing and fixing computers, programming computer software, designing database systems and graphics design.

Table 2 Perceptions regarding an IT career

\begin{tabular}{|l|l|}
\hline Positive Issues & Negative Issues \\
\hline Guaranteed a job & Update skills regularly \\
Excellent job opportunities & Health concerns \\
Good pay & Anti-social behaviour \\
Variety in tasks and & Stress \\
assignments & Reading to keep up with \\
Over seas travel & industry \\
& At a computer all day - \\
& boring \\
\hline
\end{tabular}

Only a small proportion of the participants of the focus groups indicated that they were interested in a career in computing. The most appealing thing about a career in computing was a guaranteed job. Many recognised they would need to use computers in their chosen profession but generally didn't want to be 'stuck' in front of a computer. Some indicated that they felt a career in computing involved too much continual learning. Generally, the participants recognised that a career in computing offered excellent job opportunities, good pay and plenty of variety in tasks. Participants were unsure as to whether there would be overseas travel involved.

Almost all participants had mentioned health issues relating to computing careers including sore eyes, bad posture, and obesity due to a lack of mobility, radiation, sore fingers and the risk of electrocution. The participants also generally felt that a career in computing could become quite anti social and fairly stressful.

During the follow-up interviews, the participants were able to identify several different jobs that had not been mentioned before including software engineers, communications specialists that linked schools up to the Internet and technology researchers that investigate different types of software and hardware that are useful. The participants also had a better appreciation of how people who work with computers can help business. One participant commented 'It is not just computers, a lot of them require communication skills and stuff.'

\section{CONCLUSIONS}

The conclusions of this study highlight the perceptions of young women. In particular, their interests in and frustration with computers, their 
understanding of what an IT professional does and how the Summer School influenced their perceptions about a career in IT.

The young women in this study used the computer as a tool to complete their schoolwork and for social communication. The participants mentioned games briefly but this seemed a socially required response. The participants said they became frustrated when their computer broke down and they didn't see any reason to learn new technology or software when the present tools worked well. The girls were also very aware of the health issues involved in using a computer.

Generally, the participants did not have a balanced understanding of what a computer professional does. The participants did not find a career in computing appealing as the advantages of working in the computer industry were outweighed by negative perceptions of the affects of working with computers on their health and social life and the levels of stress and self education involved. The summer school reinforced the positive perceptions of careers in computing that the participants had at the beginning of the school. Unfortunately, the summer school also appears to have reinforced many of the negative perceptions the girls had about a career in computing. There were three issues: the lack of suitable role models, too much work at a computer and computer system failure.

A lack of suitable role models was evident. The participants found that some of the presenters were anti-social in their approach. Most of the computer related activities at the summer school involved sitting at a computer in a class room scenario for the duration of the activity. From this, the participants concluded that a career in computing would involve sitting at a computer all day. Where the computer failed and the computer failure visibly upset the presenters, the participants found that in yet another instance, the tool did not work.

\section{RECOMMENDATIONS}

This study provides three recommendations for future summer school activities and perhaps for those wishing to make computing more appealing for young women.

Firstly, in computing activities that are designed to appeal to young women, the entire duration of the activity should not be spent at the computer. Perhaps information collecting activities or interviews could be included. Secondly, educate the role model, be they the interviewees or simply the activity instructor. The role model should be aware of the cultural perception that all computer professionals are unsociable and keep to them selves. To counter this perception, encourage the role model to be socially 
out-going and enthusiastic. Finally, every step should be taken to ensure that the computers used in the activity are reasonably up to date and reliable. The actions of the activity leader when a computer failure occurs are also quite important. The activities should not try to present that computer failure doesn't occur. Rather they should carry the message that computer failure can be managed and steps taken to ensure failures are minimised and cause the least disruption.

The ability to use these findings to generalise is limited to the girls attending the Girls in Maths and Science Summer School as the participants were chosen because their environmental or social circumstances [3]. Girls of a similar age but with more favourable environmental or social circumstances may not hold the same perceptions. Further research may tell us if these perceptions are limited to only those young women in these particular environmental and social circumstances or if these perceptions are more widely held.

From this study, it appears that Australian female secondary students often do not choose a career in IT because of social and health considerations. It seems that if the IT industry is serious about tapping the unused resource of women in IT they must set about influencing the perceptions of young women through educating them that a career in computing is much more than sitting at a computer for 8 hours everyday.

\section{REFERENCES}

1. Asia-Pacific IT. (January 1999). Disclaiming the Myth, Asia-Pacific IT: 8.

2. Borchers D. (1990). Europe Sees Decline in Women Computer Scientists. IEEE, 7(9), 97.

3. Brodie L. (1996). Guiding Attitudes in Career Choice: A Girls Summer School, Women in Engineering Programs Advocates Network (WEPAN), Denver, Co.

4. Brodie L. \& Walkington J. (1995). USQ Girls in Maths and Science Summer School, Second Australasian Women in Engineering Conference, Melbourne.

5. Connors E. (November 1998). IT Overlooking Its Best Resource: Women, Weekend Financial Review. pp.31.

6. Fenkel K.A. (1990). Women and Computing, Communications of the ACM, 33(1), 34-46.

7. Harrison A.W., Rainer R.K. and Hochwarter W.A. (1997). Gender Differences in Computing Activities, Journal of Social Behaviour and Personality, 12(4), 849-868.

8. Igbaria M., Baroudi J.J. (1996). The Impact of Job Performance Evaluations on Career Advancement Prospects: An Examination of Gender Differences in the IS Workplace, MIS Quarterly, 19(1), 107-124.

9. Igbaria M., Parasuraman S. and Baroudi J.J. (1996). A Motivational Mode of Microcomputer Usage, Journal of Management Information Systems, 13(1), 127-144.

10.Krueger R.A. (1994). Focus Groups: A practical Guide for Applied Research, London: Sage Publications.

11. McCloy P. (1994). Why Users Hate Your Attitude, Informatics, February, 29-35.

12. Mitchell S. (January 1998) Women Still Rejecting IT Careers, Australian Personal Computer. Pp. 28. 
13. Morgan D.L. (1998). The Focus Group Guidebook, London: Sage Publications.

14. Pearl A., Pollack M.E., Riskin E., Thomas B., Wolf E. and Wu A. (1990). Becoming a Computer Scientist, Communications of the ACM. 33(11), 47-57.

15. Rasmussen B. (1997). Girls and Computer Science: It's not me, I'm not Interested in Sitting Behind a Machine all Day. Proceedings of the 6th International IFIP-Conference Women, Work and Computerisation: Spinning a Web from Past to Future. Germany.

16. Robertson R. (1997). 'And it's a generalisation. But no it's not': Women, Communicative Work and the Discourses of Technology Design, Proceedings of the 6th International IFIP Conference on Women, Work and Computerisation, Germany.

17. Ryan C.E. (1994). Raising Girls' Awareness of Computing Careers. Proceedings of the 5th IFIP International Conference on Women, Work and Computerisation UMIST, Manchester, UK.

18. Sanders I. \& Galpin V. (1994). A Survey of Attitudes to Computing at the University of the Witwatersrand, Proceedings of the 5th IFIP International Conference on Women, Work and Computerisation, UMIST, Manchester, UK. 